\title{
Roofwater Quality Simulation in Jinan Urban Area of China
}

\author{
Haiyan Deng ${ }^{\mathrm{a}}$, Weiping Wang ${ }^{\mathrm{b}, *}$, Qiaoyi $\mathrm{Xu}^{\mathrm{c}}$ \\ School of Resources and Environment, University of Jinan, Jinan, 250022, China a denghaiyan199010@126.com, \\ bstu_wangwp@ujn.edu.cn, ${ }^{\mathrm{c}} 747929780 @$ qq.com \\ *Corresponding author. Tel: 13953162318; Address: 336, Nanxinzhuang West Road, Jinan, China
}

\begin{abstract}
There are no any feasible theoretical methods for determining the initial removal of the roofwater now, which restrains the development of the roofwater utilization to some extent. The main sources of various pollutants in the roofwater and the variation of their concentrations are analyzed with the relevant sampling and testing. Based on the data of turbidity measured from five rainfall processes occurred in Jinan of University, the parameters of the accumulation-washout model for turbidity are estimated, and then the application scope of the model is determined with the relevant verification. The relationship between the turbidity removal rate and the pollutant washout index as well as the roof runoff coefficient are derived, which provides a practical calculation method for determining the initial removal of the roofwater.
\end{abstract}

Keywords- roofwater; turbidity; accumulation-washout model; initial removal.

\section{INTRODUCTION}

The rational use of roofwater is an effective measure to resolve the water shortage in Jinan. It is of great significance to understand the roofwater quality for urban stormwater harvesting and recycling. $\mathrm{Wu} \mathrm{Che}$ [1] and Weiping Wang [2] have researched the water quality variation rules of roofwater in Beijing and Jinan respectively. There are also many foreign scholars devoted to urban rainwater quality study. Sartor et al. [3] have proposed a mathematical model of the pollutants change in the road runoff. The variation of pollutant concentration of roofwater shows some regularity because of the air quality, dust falling on the roof and rainfall characteristics, but varies from place to place.

\section{QUALITY VARIATION OF NATURAL RAINWATER AND ROOFWATER}

\section{A. Quality variation of natural rainwater}

The pollutants in natural rainwater are connected with the regional air quality. Wang Yan et al. [4] have found that the main ions in Mount Tai rainwater were $\mathrm{NH}_{4}{ }^{+}, \mathrm{SO}_{4}{ }^{2-}$, $\mathrm{Ca}^{2+}$ and $\mathrm{NO}_{3}{ }^{-}$. The pollutant concentration of initial natural rainfall was higher, then it soon became flat with rainfall decreasing.

\section{B. Quality variation of roofwater}

The pollutants in roofwater include contaminants from natural rainwater and roof dust. Compared the natural rainwater quality and roof rainwater quality in University of Jinan, the pollutants of natural rainwater and roofwater on June 1st, 2010 are shown in Tab.1 and the main pollutants concentrations of roofwater on August 1st, 2010 are shown in Fig.1.

\begin{tabular}{cccc} 
TABLE I. AVERAGE POLLUTANT CONCENTRATION OF NATURAL RAINWATER \\
\multicolumn{4}{c}{ AND ROOFWATER } \\
\hline $\begin{array}{c}\text { Monitoring } \\
\text { index }\end{array}$ & $\begin{array}{c}\text { Natural } \\
\text { rainwater }\end{array}$ & $\begin{array}{c}\text { Roof } \\
\text { rainwater }\end{array}$ & $\begin{array}{c}\text { III degree of Quality } \\
\text { standard for } \\
\text { groundwater }\end{array}$ \\
\hline Chromaticity & $<5$ & 35 & 15 \\
Turbidity/NTU & $<3$ & 18 & $\leq 3$ \\
$\mathrm{NH}_{3}-\mathrm{N} /(\mathrm{mg} / \mathrm{L})$ & 1.24 & 0.93 & $\leq 0.2$ \\
$\mathrm{NO}_{3}-\mathrm{N} /(\mathrm{mg} / \mathrm{L})$ & $<0.08$ & $<0.08$ & $\leq 20$ \\
$\mathrm{SS} /(\mathrm{mg} / \mathrm{L})$ & 40 & 288 & - \\
$\mathrm{Pb} /(\mathrm{mg} / \mathrm{L})$ & $<0.02$ & $<0.02$ & $\leq 0.05$ \\
\hline
\end{tabular}

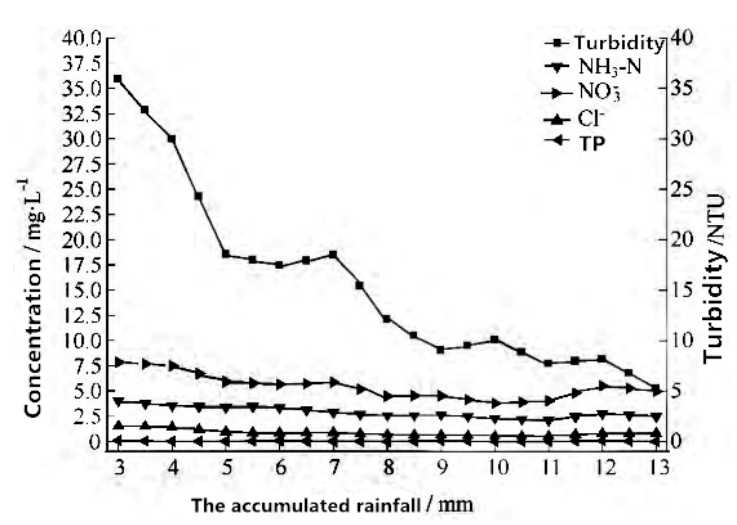

Figure 1. Concentration of main ions in roofwater

It shows that the mean values of turbidity, chroma and SS in roof rainwater are higher than that in natural rainwater in Tab.1, so it can be inferred that these three pollutants come from roof dust; The turbidity changes greatly in the whole rainfall process in Fig.1, however, other ions come from natural rainwater with the relatively stable concentration. 


\section{SIMULATION OF ROOFWATER QUALITY VARIATION}

A. Accumulation-washout model of pollutants in roofwater

The linear relationship model between roof runoff depth and precipitation is the following formula,

$$
R=\phi(V-d)(\mathrm{V}>0)
$$

Where, $\mathrm{R}$ is the accumulated runoff depth of roof runoff $(\mathrm{mm}) ; \mathrm{V}$ is the accumulated precipitation $(\mathrm{mm})$; $\varphi$ is the runoff coefficient of roofwater; $\mathrm{d}$ is the minimum precipitation forming the roof runoff $(\mathrm{mm})$.

The accumulation model of roof pollutants is

$$
P_{\mathrm{b}}=\mathrm{M}\left(1-\mathrm{e}^{-\mathrm{Neb}}\right)
$$

Where $\mathrm{P}_{\mathrm{b}}$ is the cumulative total pollutants after $\mathrm{b}$ dry days; $b$ is the duration of dry weather between two rainfall events (d); $M$ is the theoretical maximum accumulation of pollutants, which is a fixed value for the same pollutant on the same area; $\mathrm{N}_{\mathrm{e}}$ is the pollutants accumulation index. The values of $\mathrm{M}$ and $\mathrm{N}_{\mathrm{e}}$ are mainly related to the factors of the regional natural conditions and pollutants types.

The index model of flushed residual pollutant varying with the runoff depth is

$$
P=P_{b} e^{-k R}
$$

Where $\mathrm{P}$ is the residual pollutant when the cumulative runoff depth of roof rainwater reaches to be $\mathrm{R} ; \mathrm{P}_{\mathrm{b}}$ is the cumulative total pollutants after $\mathrm{b}$ days in drought; $\mathrm{R}$ is the cumulative runoff depth of roof rainwater $(\mathrm{mm}) ; \mathrm{K}$ is the washout coefficient related to pollutants types and roof condition, specific pollutants in roof is a fixed values $\left(\mathrm{mm}^{-1}\right)$

The concentration $\mathrm{C}(\mathrm{mg} / \mathrm{L})$ of roofwater pollutant is equal to the derivative of the cumulative runoff $\mathrm{Q}$ to the total residual pollutants amount $\mathrm{P}$ (the minus indicates the total residual pollutants amount $\mathrm{P}$ decreases with increased cumulative runoff), i.e.

$$
C=-\frac{d P}{d Q}=-\frac{1}{A} \frac{d P}{d R}
$$

Where, $\mathrm{Q}$ is the cumulative runoff of roofwater $\left(\mathrm{m}^{3}\right)$; A is the catchment area of roof $\left(\mathrm{m}^{2}\right)$; $\mathrm{R}$ is the cumulative runoff depth $(\mathrm{m})$; $\mathrm{C}$ is the instantaneous concentration of pollutants when the cumulative runoff of roofwater is $Q$ (or cumulative runoff depth is $\mathrm{R})(\mathrm{mg} / \mathrm{L})$.

The calculation formula of the instantaneous concentration of roofwater, as the following,

$$
C=C_{b} e^{-K R}
$$

Where, $\quad C_{b}=\frac{k P_{b}}{A} \quad$ is the initial maximum concentration of pollutants in the roofwater.

The formula of roofwater pollutants accumulation-washout (6) is derived with substituting formula (1) and (2) into the formula (5).

$$
C=\frac{k M\left(1-e^{-N_{e} b}\right)}{A} e^{-k \varphi(\mathrm{v}-\mathrm{d})}(\mathrm{V}>0)
$$

$\mathrm{K}$ is the washout index $\left(\mathrm{mm}^{-1}\right) ; \mathrm{C}, \mathrm{b}$ and $\mathrm{V}$ are the observed values.

\section{B. Parameter estimation of turbidity accumulation-washout model in roofwater}

The turbidity dates of 5 typical rainfall events in NO.1 teaching building of University of Jinan in July and August, 2012 were observed and recorded. The water samples from initial $15 \mathrm{~mm}$ rainfall were tested (Tab.2).

\begin{tabular}{|c|c|c|c|c|}
\hline time & $\begin{array}{c}\text { initial } \\
\text { turbidity } \\
\mathrm{C}_{\mathrm{b}} / \mathrm{NTU} \\
\end{array}$ & $\begin{array}{c}95 \% \\
\text { confidence } \\
\text { interval }\end{array}$ & $\begin{array}{l}\text { washout } \\
\text { index } \mathrm{k}\end{array}$ & $\begin{array}{c}95 \% \\
\text { confidence } \\
\text { interval }\end{array}$ \\
\hline 1 & 51.07 & $(46.21,55.93)$ & 0.1559 & $\begin{array}{l}0.1343, \\
0.1774)\end{array}$ \\
\hline 2 & 39.79 & $(36.29,43.28)$ & 0.1314 & $\begin{array}{l}(0.1134 \\
0.1494)\end{array}$ \\
\hline 3 & 32.86 & $(30.24,35.49)$ & 0.1498 & $\begin{array}{c}(0.1321, \\
0.1673)\end{array}$ \\
\hline 4 & 48.86 & $(47.07,50.66)$ & 0.1537 & $\begin{array}{c}(0.1449 \\
0.1613)\end{array}$ \\
\hline 5 & 36.58 & $(34.01,39.14)$ & 0.1653 & $\begin{array}{l}(0.1489 \\
0.1818)\end{array}$ \\
\hline
\end{tabular}

TABLE II. TURBIDITY CHANGES OF INITIAL 15MM RAINFALL IN THE FLOOD SEASON

\begin{tabular}{cccccc}
\hline & \multicolumn{5}{c}{ Turbidity /NTU } \\
\cline { 2 - 6 } precipitation/mm & $\begin{array}{c}1^{\text {st }} \\
\text { time }\end{array}$ & $\begin{array}{c}2^{\text {nd }} \\
\text { time }\end{array}$ & $\begin{array}{c}3^{\text {rd }} \\
\text { time }\end{array}$ & $\begin{array}{c}4^{\text {th }} \\
\text { time }\end{array}$ & $\begin{array}{c}5^{\text {th }} \\
\text { time }\end{array}$ \\
\hline 1 & 45.6 & 38.3 & 29.5 & 42.7 & 32.6 \\
2 & 40.2 & 32.5 & 25.3 & 36.4 & 27.5 \\
3 & 34.6 & 27.4 & 22.5 & 33.6 & 23.4 \\
4 & 28.7 & 22.2 & 18.7 & 28.8 & 19.7 \\
5 & 23.1 & 19.8 & 16.2 & 24.3 & 16.3 \\
6 & 18.7 & 17.4 & 14.8 & 22.7 & 14.2 \\
7 & 16.3 & 16.3 & 11.3 & 17.8 & 12.5 \\
8 & 14.2 & 14.1 & 9.8 & 16.1 & 9.7 \\
9 & 13.9 & 13.7 & 8.1 & 13.2 & 8.2 \\
10 & 11.5 & 12.6 & 7.5 & 11.6 & 7.9 \\
11 & 12.6 & 11.7 & 7.4 & 10.3 & 7.5 \\
12 & 11.7 & 10.4 & 7.6 & 9.7 & 7.3 \\
13 & 10.4 & 9.8 & 7.3 & 8.2 & 6.4 \\
14 & 10.3 & 10.1 & 6.8 & 8.3 & 6.7 \\
15 & 10.4 & 9.4 & 6.9 & 8.1 & 6.2 \\
\hline
\end{tabular}

TABLE III. INITIAL TURBIDITY AND WASHOUT INDEX OF EACH RAINFALL EVENT

Roofwater runoff was produced at the beginning of rainfall because the roofing material is ceramic tile. The runoff coefficientyand the minimum rainfall producing runoff $\mathrm{d}$ were respectively 0.9 and 0.0 . The formula (6) is simplified as $C=C_{b} e^{-k q v}=C_{b} e^{-0.9 k v}$, which $C_{b}=\frac{k M\left(1-e^{-N_{e} b}\right)}{A}$ is the initial maximum turbidity. The initial turbidity value and washout index of roofwater in each rainfall event were calculated with the nonlinear parameter estimation method according to the turbidity dates of 5 typical rainfall events (Tab.3).

The five rainfall events were the typical in flood season, so the average value of turbidity washout index $\mathrm{K}(0.1511)$ can represent roofwater turbidity washout index in the whole flood season. The calculation formula of initial turbidity value of initial rainfall is 


$$
C_{b}=\frac{k M\left(1-e^{-N_{e} b}\right)}{A}=C_{M}\left(1-e^{-N_{e} b}\right)
$$

$C_{M}=k M / A$ is the theoretical maximum turbidity of roofwater, and other parameters are same as above. The drought days were respectively $10,7,3,9$ and 5 days in the five rainfall events, and $C_{M}=52.04, N_{e}=0.2732$ with the least square fitting

\section{MODEL VERIFICATION}

The turbidity dates of roof runoff from two rainfall events on August $22^{\text {th }}$ and $28^{\text {th }}, 2012$ were used to verify the model, with the sunny day before the rain were 8 and 6 days, the result is shown in Fig.2.

It showed a better conformation to the regularity of accumulation-washout for the simulated data and the measured data of initial and medium-term rainfall event in Fig.2; And the dates did not fit the exponential law with the reduction of roof dust pollutants, but stable in the turbidity data of natural water during late stage of measured rainfall event. So the accumulation-washout model is only suitable for the initial and medium-term rainfall event, which is used for calculating the initial removal of roofwater.
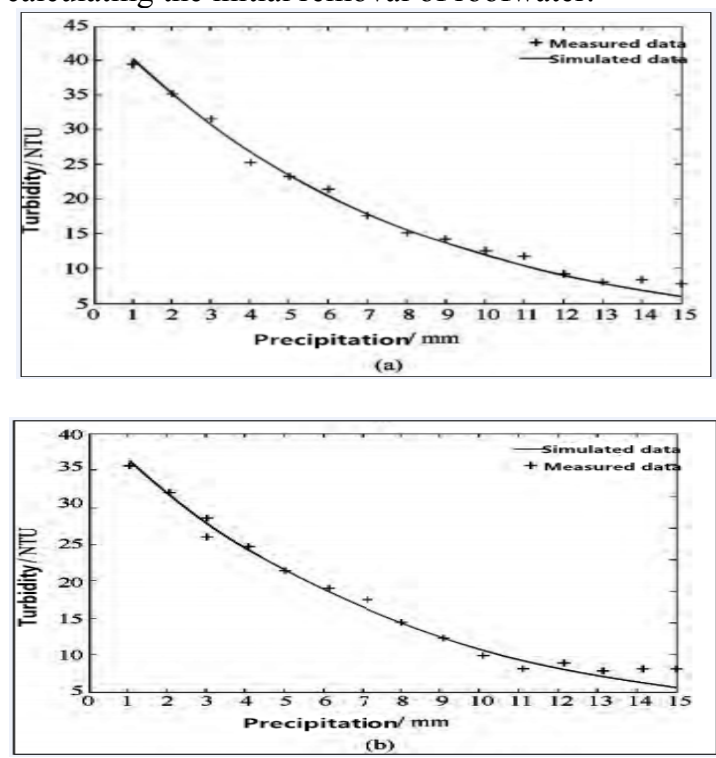

Figure 2. Test results of turbidity accumulation-washout model

\section{V.INITIAL REMOVAL}

The turbidity removal rate was defined as the ratio of turbidity of initial removal to the total turbidity of the whole roof runoff. Based on the assumption that the cumulative rainfall of a whole rainfall process was $Q$, the initial removal was q, the following formula was derived with the integration and division of the cumulative-washout model on the data $(0, Q)$ and $(0, q)$.

$$
N=\frac{\int_{0}^{q} C_{M}\left(1-e^{-N_{e} b}\right) e^{-k \varphi(v-\mathrm{d})} d v}{\int_{0}^{Q} C_{M}\left(1-e^{-N_{e} b}\right) e^{-k \varphi(\mathrm{v}-\mathrm{d})} d v}=\frac{1-e^{-k \varphi q}}{1-e^{-k \varphi Q}}(Q>q>0)
$$

Where, $\mathrm{N}$ is turbidity removal rate; $\mathrm{q}$ is initial removal $(\mathrm{mm})$; Q is cumulative rainfall $(\mathrm{mm})$.

Turbidity removal rate increases with the increase of initial removal. However, a large amount of initial removal will cause the rainwater waste, so these two dates should be determined according to balance between economy and water saving. The first flush removal of $6 \mathrm{~mm}$ for artificial recharge of groundwater with roofwater is recommended.

\section{CONCLUSION}

According to the quality simulation of roofwater on the NO.1 building of Jinan University, it was shown that the pollutants sources of roofwater were mainly resulted from natural rainfall and roof dust. the variation regularity of turbidity varying with rainfall event caused by roof dust was simulated, the accumulation-washout model was established which was used for primary determination of the initial removal.

\section{ACKNOWLEDGMENTS}

This study was supported by the National Natural Science Foundation of China (40972169).

\section{REFERENCES}

[1] Che Wu, Wang Hui-Zhen \& Ren Chao. Study on roofwater pollution and utilization of Beijing urban. China Water \& Wastewater, 17(6), pp.57-61, 2001.

[2] Wang Wei-Ping, Qu Shi-Song \& Ye Xin-Qiang. Quality characteristics of roof rainwater for fracture-karst aquifer recharge. Journal of Hydraulic Engineering,42(4), pp.477-482, 2011.

[3] Sartor J. D, Boyd G. B \& Agardy F. Water pollution aspects of street surface contaminants. Water Pollute. Control Fed, 46(3), pp.458-467, 1974.

[4] Wang Yan, Ge Fu-Ling \& Liu Xiao-Huan. Analysis of ionic composition characteristics of precipitation at Mount Taishan. China Environmental Science, 26(4), pp.422-426, 2006. 